\title{
Patient-Physician Shared Experiences and Value Patients Place on Continuity of Care
}

\author{
Arcb G. Mainous III, $P b D^{1}$ \\ Meredith A. Goodwin, $P b D^{2}$ \\ Kurt C. Stange, $M D, P b D^{2}$ \\ 'Department of Family Medicine, Medical \\ University of South Carolina, Charleston, SC \\ ${ }^{2}$ Department of Family Medicine, Case \\ Western Reserve University, Cleveland, Ohio
}

\begin{abstract}
PURPOSE We undertook a study to examine the impact of experiences shared between patient and physician and the value patients place on continuity of care.

METHODS Data on 4,454 patients collected in The Direct Observation of Primary Care (DOPC) study conducted between October 1994 and August 1995 were analyzed to assess the value patients place on continuity, length of patient-physician relationship, and experiences shared between patient and physician.
\end{abstract}

RESULTS A significant interaction was yielded between duration of relationship and experiences shared between patient and physician $(P=.03)$. For all lengths of relationship with the physician, the value that patients have for continuity increased when patients indicated experiences shared with the physician. For patients who did not report experiences shared with the physician, the longer the relationship, the greater the value placed on continuity.

CONCLUSIONS The results of this study point to the importance of the experiences shared between patients and physicians and the value that patients place on continuity with their regular physician.

Ann Fam Med 2004;2:452-454. DOI: 10.1370/afm.84

\section{INTRODUCTION}

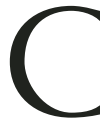

ontinuity of care plays a central role in the patient-physician relationship and has been shown to be associated with a variety of hospitalization and emergency department use, ${ }^{2,3}$ and control of chronic disease. ${ }^{4}$ Consequently, from a health policy perspective continuity of care has been encouraged for many years. ${ }^{5}$

It is unclear what creates a patient's desire for continuity of care. ${ }^{1}$ For example, patients with asthma have a greater desire than the general population to maintain continuity with their physician, even when the visit is not for asthma. ${ }^{6}$ Asthmatic patients have frequent contacts with their physician, but they may also link successful resolution of an exacerbation to the skill of the physician. The purpose of this study is to examine the independent and interactive impact of longitudinal physician continuity and shared experiences of patients and physicians on patients' desires for continuity of care.

\section{METHODS}

\section{Sample}

These analyses use data from The Direct Observation of Primary Care (DOPC) Study, which was a multimethod, cross-sectional study of outpatient visits to family physicians conducted between October 1994 and August $1995 .^{7}$ The sample consisted of 138 family physicians and 4,454 patients. 


\section{Measures}

Degree to Which Patients Value Continuity

The patient's value of continuity was determined by 3 self-reported items: "My medical care improves when I see the same doctor that I have seen before," "It is very important to me to see my regular doctor," and "I want one doctor to coordinate all of the health care I receive" ( $1=$ strongly disagree $;=$ strongly agree). The responses to the 3 items were averaged to create an index (Chronbach's $\alpha=.67$ ).

Shared Experience Between Patient and Physician Experiences shared between patients and physicians were measured by the following self-reported item: "This doctor and I have been through a lot together" ( $1=$ strongly disagree $;=$ strongly agree). The responses were collapsed into 3 categories of agreement (disagree, neutral, and agree).

\section{Length of Patient-Physician Relationship}

The length of the patient-physician relationship was measured according to patient self-report as less than 2 years, 2 to 4 years, and more than 4 years.

\section{Covariates}

Several variables have been previously found to be bivariately associated with patients valuing continuity, including patient age, sex, race, educational level attained, health status, number of visits in previous

Table 1. Association Between Duration of Patient-Physician Relationship, Experiences Shared Between Patient and Physician, and the Degree to Which Patients Value Continuity of Care ( $N=2,504)$

\begin{tabular}{lrrrr}
\hline Covariates & $\begin{array}{c}\text { Sum of } \\
\text { Squares }\end{array}$ & df & F & P \\
\hline Age & 0.66 & 1 & 1.47 & .226 \\
Sex & 0.85 & 1 & 1.89 & .17 \\
Health status & 1.92 & 1 & 4.27 & .04 \\
Number of visits in previous year & 23.00 & 1 & 51.14 & $<.001$ \\
Number of chronic illnesses & 3.01 & 1 & 6.69 & .010 \\
Number of medications & 1.37 & 1 & 3.05 & .081 \\
Insurance* & & & & \\
Medicare & 6.44 & 1 & 14.31 & $<.001$ \\
Medicaid & 1.21 & 1 & 2.69 & .10 \\
Managed care & 1.59 & 1 & 3.54 & .06 \\
None or other & 1.69 & 1 & 3.76 & .05 \\
Main effects (combined) & 96.38 & 4 & 53.58 & $<.001$ \\
Been through a lot with doctor & 84.56 & 2 & 42.28 & $<.001$ \\
Number of years as patient of physician & 0.85 & 2 & 0.43 & .39 \\
Two-way Interaction & 4.74 & 4 & 2.64 & .03 \\
Model & 196.30 & 18 & 24.25 & $<.001$ \\
Residual & $1,117.53$ & 2,485 & & \\
Total & $1,313.83$ & 2,503 & & \\
\hline * Reference category is fee-for-service insurance. & & & & \\
\hline
\end{tabular}

year, number of medications, number of chronic illnesses, and type of insurance. Self-reported health status was measured on the patient exit questionnaire using a 5 -item index modified from the Medical Outcome Study 6-item General Health Survey. ${ }^{8}$

Linear regression using backward selection of value of continuity onto the potential covariates was used to determine which covariates were independently associated with patients valuing continuity and thereby needed for adjustment.

\section{Analyses}

The relationship between the duration of relationship with the physician and a key event with physician (independent variables) with value of continuity (dependent variable) was analyzed using a 2 -way analysis of variance while controlling for the confounding variables.

\section{RESULTS}

The demographics of the patient and physician samples have been previously described. ${ }^{7}$ The results of the 2 way analysis of variance testing the effects of duration of relationship with the physician and experiences shared between patients and physicians on the degree to which patients value continuity are displayed in Table 1. A significant interaction was found between duration of relationship and experiences shared between patients and physicians. The effect of experiences shared with the physician on the degree to which patients value continuity is dependent on the length of the patient's relationship with the physician, and vice versa.

This complex relationship between duration of relationship, experiences shared between patient and physician, and the degree to which patients value continuity can be better understood by examining the mean value of continuity within each of the cells of the independent variables, as displayed in Table 2. For all lengths of relationship with the physician, the patients' value of continuity increased when patients had a shared experience with the physician. Also, for all 3 categories of key event, the patient's value of continuity was higher when the patient had been with the physician for more than 4 years than when the patient had 


\begin{tabular}{|c|c|c|c|c|}
\hline \multirow[b]{2}{*}{$\begin{array}{l}\text { Duration of } \\
\text { Relationship }\end{array}$} & \multicolumn{4}{|c|}{ Doctor and I Have Been Through a Lot Together } \\
\hline & $\begin{array}{c}\text { Disagree, } \\
\text { Strongly Disagree } \\
(\mathrm{n}=690)\end{array}$ & $\begin{array}{c}\text { Neutral } \\
(n=895)\end{array}$ & $\begin{array}{c}\text { Agree, } \\
\text { Strongly Agree } \\
(\mathrm{n}=919)\end{array}$ & $\begin{array}{c}\text { Total } \\
(\mathrm{n}=2,504)\end{array}$ \\
\hline $\begin{array}{l}\text { Less than } 2 \text { years } \\
(\mathrm{n}=597)\end{array}$ & 4.04 & 4.31 & 4.61 & 4.23 \\
\hline $2-4$ years $(n=834)$ & 4.03 & 4.39 & 4.72 & 4.40 \\
\hline $\begin{array}{l}\text { More than } 4 \text { years } \\
\quad(\mathrm{n}=1,073)\end{array}$ & 4.25 & 4.35 & 4.74 & 4.54 \\
\hline Total $(\mathrm{N}=2,504)$ & 4.10 & 4.36 & 4.72 & 4.42 \\
\hline
\end{tabular}

been with the physician for less than 2 years. Magnitude of difference, however, was not the same for all levels of key event. For patients who responded that they did not have a shared experience with the physician, the difference in value of continuity by length of relationship appeared to be greater than for patients that agreed or responded neutrally.

\section{DISCUSSION}

The results of this study point to the importance of the patient-physician relationship in a patient's desire for continuity with his or her regular doctor. Just seeing the same physician over time does not guarantee a personal relationship or loyalty on the part of the patient.

This finding dovetails with previous discussions suggesting that the construct of continuity of care needs to be conceptualized in a way that distinguishes contact between patient and physician from the development of personal relationships. ${ }^{1}$ The personal relationship has been argued to be more important than simply having exposure to the same physician. Some physicians develop relationships within a short period, whereas others may see patients for years and still not have developed a strong patient-physician relationship. The developing relationship may be tied, however, to the successful management of important medical problems. The data support past research that suggests patients who have medical problems requiring substantial intervention on the part of the physician are more likely to exhibit a desire for continuity. ${ }^{6}$

The results of this study must be evaluated in light of several limitations. First, the data are all based on self-reports and thereby could be influenced by recall bias or social desirability. Even so, many of the measures have been previously validated and used successfully in other studies. Second, the data may be somewhat dated because they derive from surveys conducted in August 82003.
1994 and 1995. It is possible that the relationships may not represent current attitudes, although it seems unlikely that this process of developing relationships between patients and physicians would have changed substantially in the recent past. Third, the analysis is cross-sectional and thereby limits our ability to demonstrate causal pathways between the constructs of experiences shared between patients and physicians and how patients value continuity.

In conclusion, the present findings point to the importance of experiences shared between patients and physicians. The longitudinal relationship that can build between patients and physicians is enhanced by these shared experiences. Future research might elucidate the types of shared experiences that encourage a desire for continuity of care.

To read or post commentaries in response to this article, see it online at http://www.annfammed.org/cgi/content/full/2/5/452.

Key words: Continuity of patient care; physician patient relationship; critical incident; patient satisfaction

Submitted April 21, 2003; submitted, revised, July 21, 2003; accepted

Funding support: This research was supported by grants from the National Cancer Institute (1 R01 CA80862, 2 R01 CA80862, K24 (A81031) and by a Family Practice Research Center grant from the American Academy of Family Physicians.

\section{References}

1. Freeman G, Hjortdahl P. What future for continuity of care in general practice? BMJ. 1997;314:1870-1873.

2. Mainous AG III, Gill JM. The importance of continuity of care in the likelihood of future hospitalization: is site of care equivalent to a primary clinician? Am J Public Health. 1998;88:1539-1541.

3. Gill JM, Mainous AG III, Nsereko M. The impact of continuity of care on emergency department utilization. Arch Fam Med. 2000;9:333-338

4. Parchman ML, Pugh JA, Noel PH, Larme AC. Continuity of care, selfmanagement behaviors, and glucose control in patients with type 2 diabetes. Med Care. 2002;40:137-144.

5. Donaldson MS, Yordy KD, Lohr KN. Vaneslow NA, eds. Primary Care: America's Health in a New Era. Washington, DC: National Academy Press; 1996.

6. Love MM, Mainous AG III. Commitment to a regular physician: how long will patients wait to see their own physician for acute illness? J Fam Pract. 1999;48:202-207.

7. Stange KC, Zyzanski SJ, Smith TF, et al. How valid are medical records and patient questionnaires for physician profiling and health services research? A comparison with direct observation of patient visits. Med Care. 1998;851-867.

8. Ware J, Nelson E, Sherbourne C, et al. Preliminary tests of a 6-item general health survey: a patient application. In: Ware ASJ, ed. Measuring Functioning and Well-Being. Durham, NC: Duke University Press; 1992:291-307. 